\title{
Automatic Voltage Regulator as a Voltage Control in 1 Phase Axial Generator System
}

\author{
Yosi Apriani ${ }^{1}$, Zulkiffli Saleh ${ }^{2}$, Suppermen ${ }^{3}$, Ian Mochamad Sofian ${ }^{4}$ \\ 1, 2,3 Department of Electrical Engineering, Universitas Muhammadiyah Palembang, Palembang, Indonesia \\ ${ }^{4}$ Department of Nautical Technology, Inland Water and Ferries Transport Polytechnic of Palembang, Indonesia \\ Email: ${ }^{1 *}$ yosi_apriani@um-palembang.ac.id \\ *Corresponding Author
}

\begin{abstract}
A constant output voltage on a generator is very important to produce the expected power supply. Changes in the output voltage of a generator are influenced by various disturbing factors, one of which is load and Rotations Per Minute (RPM) which are not always constant. Therefore, we need a special regulator equipment to keep the generator output voltage constant. The problem of voltage instability during load changes must be overcome to keep the voltage constant, so that equipment is needed that can control the voltage stability. This tool is the Automatic Voltage Regulator (AVR). The purpose of this study is to design a voltage control device in a single-phase axial generator system. The research method used consists of 3 stages, namely: 1). Design and design of tools, 2). Stages of making tools, 3). Stages of testing the tool. The results of the research were obtained when an axial generator with an inner air gap of $0.4 \mathrm{~cm}$, outer $0.5 \mathrm{~cm}$ and $\mathrm{rpm} 2589$. The output voltage of the generator began to decrease significantly until it reached -70 volts and rpm also decreased to $-\mathbf{2 0 0}$. In contrast, when the generator is operated using the AVR, the reduction only reaches $\mathbf{- 3 0}$ volts. However, when the generator is operated with AVR, the decrease in $\mathbf{~ r p m}$ is greater until it reaches $\mathbf{- 2 2 0}$.
\end{abstract}

Keywords-Automatic Voltage Regulator, voltage, axial generato, rotor

\section{INTRODUCTION}

Generators that are often found in the market are highspeed induction generators, in this type of generators require high rotation and initial electrical energy to create the magnetic field [1][2][3][4]. As the radial type generator, the torus model is one type of generator that operates at speeds above $1500 \mathrm{rpm}$ which uses the Internal Combustion Engine (ICE) such power as the main propulsion diesel generator rotor [5][6][7].

Low-speed generators that are widely used are axial flux type generators [8][9][10]. Axial flux generators are very efficient to use because they can work well at low rotational speeds [11]. Ease of manufacture and scale-up of a permanent magnet generator become a consideration in designing the generator with a capacity of certain power, a certain tension and a pace of work specified only by changing parameters such as the strength of the magnetic flux, number of reels and coils, and also the number of magnets and wire diameter sizes [12][13]. Generator flux axial type rotor double stator single is one of the developments of the axial flux generator [14][15].

A constant output voltage in the generator is very important to produce the expected power supply
$[16][17][18][19]$. Changes in the output voltage of a generator are influenced by a variety of confounding factors, one of that is the loads and Rotations Per Minute (RPM) which are not always constant [20].

Then the parameters of the plant, there must be a tool that can be regulated so that the plant continues to operate well by continuing to supply loads in safe and stable conditions. Nowadays, there is equipment that can set the parameters of the generator and work automatically. One type of quipment is the Automatic Voltage Regulator (AVR) in such a way as to be able to regulate the value of the voltage generated by a generator.

\section{LITERATURE REVIEW}

The axial generator is one type of electric engine that can generate electrical energy with the direction of the flux flow perpendicularly [21][22]. This type of generator continues to be developed with a variety of design variations to obtain a high level of efficiency to be implemented with existing natural resources. Generator flux axial type rotor double stator single without iron core is one of the developments of axial flux generator [23][24][25][26]. This generator is usually used for the generation of electrical energy at low rotations. This generator uses a double rotor flanking the stator in the middle. The stator part is a coil without an iron core while the rotor part consists of several pairs of a permanent magnet that function as the main field generator. The greater the surface area of the permanent magnets are used, the more the magnetic flux is generated by the magnet permanent and penetrate the coil on the stator so that the induced electromotive force (GGL) is also getting higher.

\section{A. The Working Principle of Axial Generator}

Based on the law of faraday, if a reel or coil of wire and then there is a magnet that is moved or vice versa, a magnetic flux will arise which flows on the coil caused by induced GGL, the flow of magnetic flux that flows in the coil called as the current flow, while the induced GGL changes at the lowers of the coil as a potential or voltage difference. Based on the electromotive force or voltage that causes an electric current proportional to the rate of change of magnetic flux through the coil. If written mathematically is as follows: 


$$
E i=-N \times \frac{\Delta \theta}{\Delta t}
$$

Where:

$$
\begin{aligned}
E i & =\text { Induction } \\
N & =\text { Tum (Weber) } \\
\Delta \theta & =\text { Magnetic flux (Wb) } \\
\Delta t & =\text { Time change (second) }
\end{aligned}
$$

\section{B. Axial Generator Design}

The power supply circuit is used to supply direct current /voltage for electronic devices that require DC supply. Electronic devices that require power supplies are Arduino, drive relays. The required voltage is $12 \mathrm{Vdc}$, but the recommended one is $7-12 \mathrm{Vdc}$, so a power supply/adapter with an output of $12 \mathrm{Vdc}$ is used.

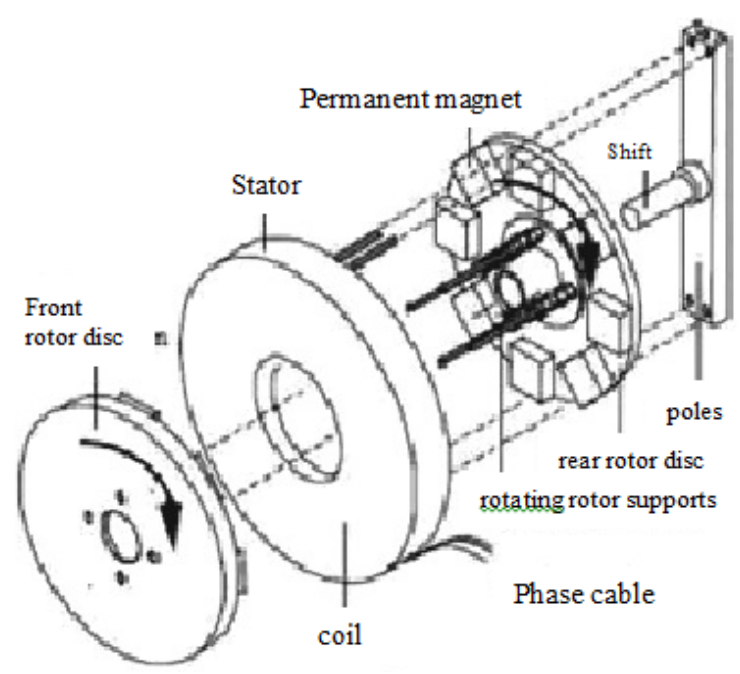

Fig. 1. Axial generator.

In general, the overall design of the generator (Figure 1) has several important parts including the following:

\section{Rotor}

The rotor (Figure 2) is a part of a rotating generator consisting of a circular arrangement of permanent magnets with different sides $(\mathrm{N}, \mathrm{S}, \mathrm{N}, \mathrm{S})$. For the design of the rotor on a 1 phase generator, the number of magnets used amounts to 2 of many coils that will be used. The number of magnets to be used is 16 for each rotor.

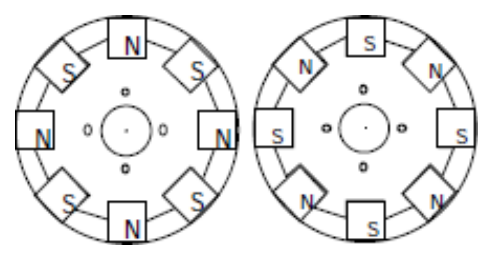

Fig. 2. Rotor design

\section{Stator}

Stator (Figure 3) is the part that does not rotate (static), in the stator generator there are conductor turns arranged under the rules of both the number of turns, the distance between the windings (pitch factor) and the angular difference between phases, to produce voltage phase 3 which has an angle of 120 degrees to other phases. The ability and quality of the generator are also determined by the copper material that used and the level of insulation resistance to heat through it. On this stator, there are 9 coils with 220 turns per coil and a large diameter wire of $0.70 \mathrm{~mm}$.

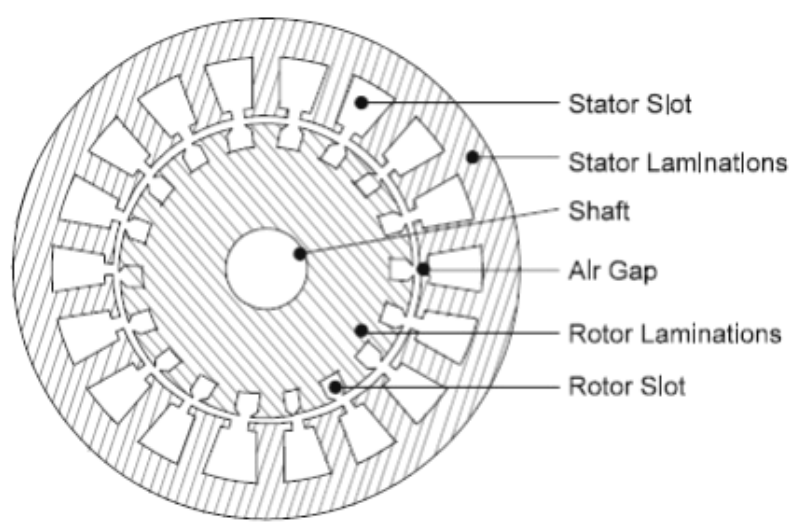

Fig. 3. Stator design

\section{Air Gap}

The reduction of the total air gap (Figure 4) can be achieved by minimizing the thickness of the resin layer over the magnet and the stator, to produce a higher induction voltage and a higher power output.

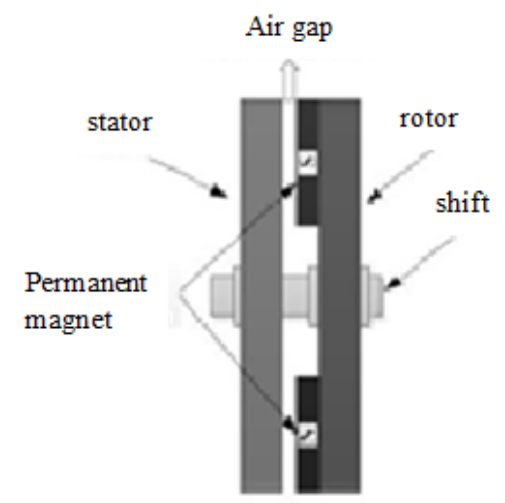

Fig. 4. Axial air gap generator

\section{Automatic Voltage Regulator (AVR)}

Automatic voltage regulator (AVR) is a device mounted on a generator that can work automatically regulating the voltage or amplitude of the waves generated by the generator to keep stable. AVR works in regulating the output voltage of the generator by controlling the gain of current from the generator. The automatic voltage regulator system diagram is shown in Figure 5. 


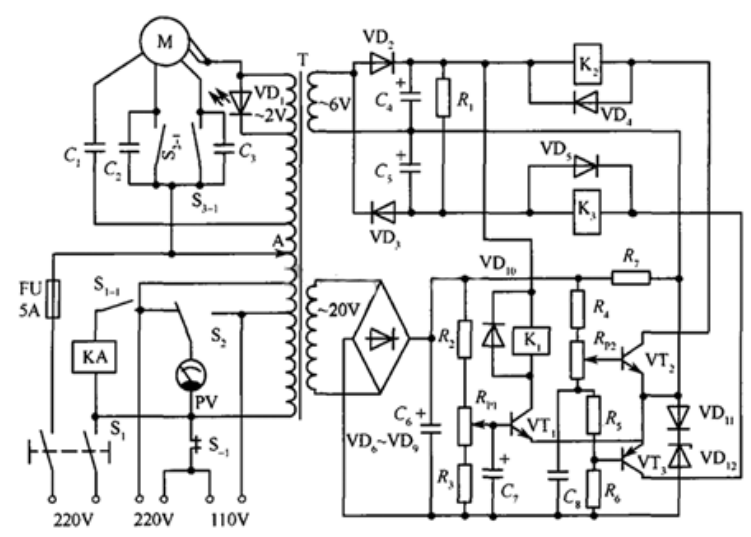

Fig. 5. AVR system diagram.

The main component is the mechanism of tap changing and its control. Each AVR is usually equipped with equipment that can control tap changes automatically based on the incoming voltage even though at that time the AVR is in a state of burden. To determine a single-phase regulator rating can be determined using the following equation:

\section{AVR Function}

1. Maintain the stability of the output voltage of the generator;

2. Arrange the division of pseudo-directive power when working in parallel;

3. Provide regulating the flow of excitation in conditions of interference so as not to come out of synchronization;

4. Lowering the voltage quickly when the generator regardless of the load which would conduce overvoltage happened.

\section{AVR Working Principle}

If the output voltage of the generator below the normal voltage generator voltage, the AVR will increase the flow of reinforcement (excitation) on the exciter. Thus, if there is a change in the output voltage of the generator will be automatically stabilized by the AVR because it is equipped with equipment such as tools used for minimum or maximum restrictions that work automatically. Three AVR states, namely:

1. If the output voltage is high, the AVR error signal (+) will give commands to reduce the excitation current.

2. If the voltage matches the setpoint value (0) then the AVR will not give any orders.

If the output voltage is low then the error signal will (-) then the AVR will give the command to add the excitation current.

\section{RESEARCH METHOD}

\section{A. Fishbone Diagram}

Fishbone diagram is shown in Figure 6. There is some part such as axial generator, electrical part, tools and material.

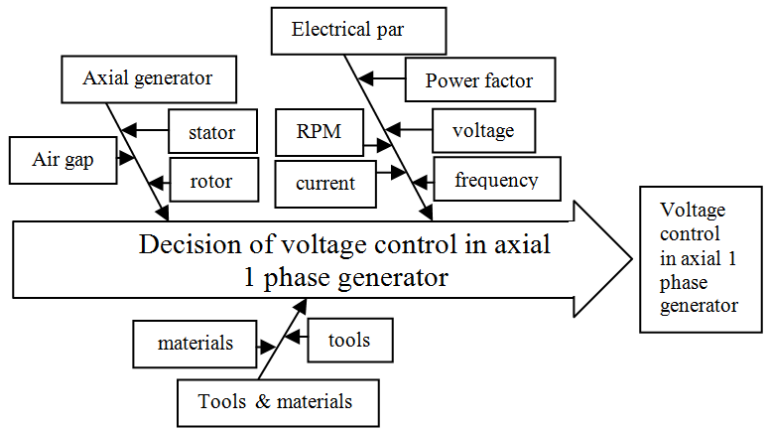

Fig 6. Fishbone diagram

\section{B. Data Collection Method}

Water flow velocity data retrieval and power calculation are available to determine the potential used to turn the Archimedes turbine and the turbine will rotate the axial generator and discharge output electrical energy of generator can be raised with a step-up regulator to use 220 volts voltage, then stabilize the voltage using AVR. Like the picture in Figure 7.

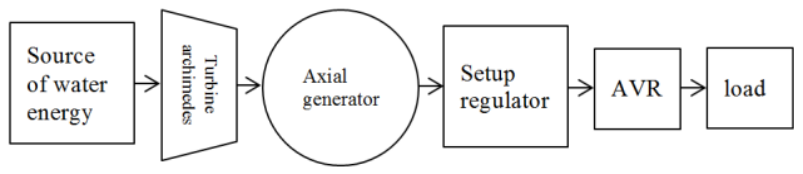

Fig 7. Block diagram.

\section{DATA AND ANALYSIS}

\section{A. Automatic Voltage Regulator (AVR) Scheme}

The automatic voltage regulator (AVR) circuit schematic is shown in Figure 8.

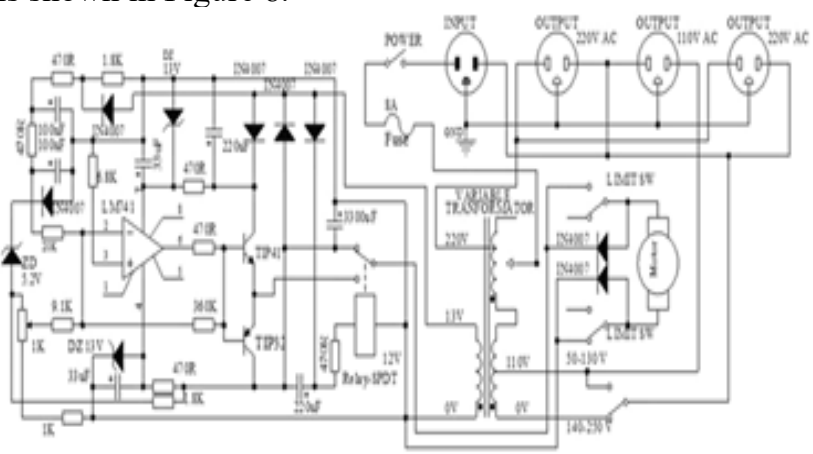

Fig. 8. Automatic Voltage Regulator (AVR) Circuit Scheme.

\section{B. AVR 1000VA Works}

In the on state, AVR always adjusts the output voltage automatically with changes in input electric voltage. If the input voltage is less than 220 volts, the AVR strengthens Step Up. Vice Versa, if the input voltage is more than 220 volts, the AVR reduces Step Down. When the AVR is turned off when the utility voltages are less than 220 volts, the AVR ready to use in the next use in the Step-Up position. If when the AVR has turned on again, the electric voltage is more than 220 volts. Then the AVR Output will come out very high 
voltage. Even though the incident was only for a moment because the AVR will immediately make adjustments but it is quite dangerous for electronic devices connected to the AVR.

\section{Analysis}

1. Measurement of the axial generator with an inner air gap $0.7 \mathrm{~cm}$ and outer $0.6 \mathrm{~cm}$.

a. Measurement without using AVR on the axial generator using inner air gap $0.7 \mathrm{~cm}$ and outer $0.6 \mathrm{~cm}$.

In this trial phase, the axial generator is given an initial rpm of 2580 with an inner air gap of $0.7 \mathrm{~cm}$ and an outer 0.6 $\mathrm{cm}$. Furthermore, the generator is given a gradual increase in load to produce the data tests without using AVR in Table 1 and Figure 9.

TABLE I. DATA TEST WITHOUT USING AVR

\begin{tabular}{|c|c|c|c|c|}
\hline $\begin{array}{c}\text { Rotation } \\
\text { (rpm) }\end{array}$ & $\begin{array}{c}\text { Axial } \\
\text { Generator } \\
\text { (Volt) }\end{array}$ & $\begin{array}{c}\text { Trafo } \\
\text { (Volt) }\end{array}$ & $\begin{array}{c}\text { Current } \\
\text { (Ampere) }\end{array}$ & $\begin{array}{c}\text { Load } \\
\text { (Watt) }\end{array}$ \\
\hline 2580 & 26.7 & 206 & 0.00 & 0 \\
\hline 2550 & 20.3 & 157 & 0.05 & 15 \\
\hline 2540 & 14.4 & 111 & 0.09 & 30 \\
\hline 2470 & 10.4 & 079 & 0.11 & 45 \\
\hline 2450 & 07.8 & 058 & 0.12 & 60 \\
\hline
\end{tabular}

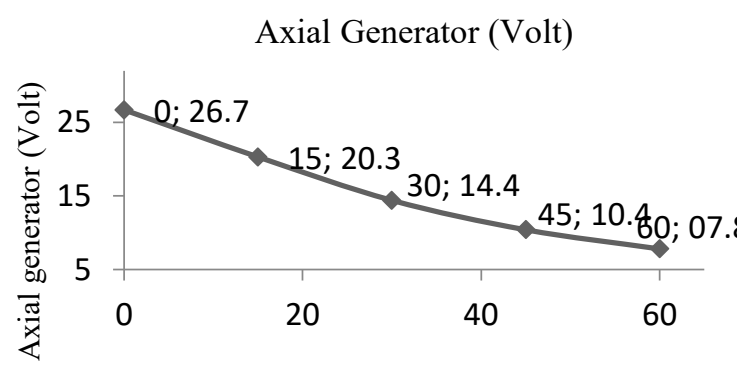

Load (Watt)

Fig. 9. Axial generator load voltage graph.

When the generator is operated without AVR and given a gradual increase in load starting from 15 watts to 60 watts with $0.7 \mathrm{~cm}$ inner air gap, outer $0.6 \mathrm{~cm}$, and $2580 \mathrm{rpm}$. When the load is above 15 watts and has reached 60 watts then the output voltage regulator began to decrease significantly until it reaches -40 volts and the rpm also decreased to -100 .

b. Testing using AVR in axial generator with inner air gap $0.7 \mathrm{~cm}$ and outer $0.6 \mathrm{~cm}$.

In this test phase, the generator is given an initial rpm of 2580 with an inner air gap of $0.7 \mathrm{~cm}$ and an outer $0.6 \mathrm{~cm}$. Furthermore, the generator is given a gradual increase in load to produce data tests using AVR in Table II.

When the generator is operated using AVR and given a gradual increase in load starting from 15 watts to 60 watts with an inner air gap $0.7 \mathrm{~cm}$, an outer $0.6 \mathrm{~cm}$, and rpm of 2580. When the load is above 15 watts and has reached 60 watts, the output voltage started to decrease but it is not as high as when the generator is operated without using AVR.
The decreasing of the Output voltage generator just reaches 30 volt. In contrast to when the generator is operated without using AVR, the decrease reaches to -40 volts. However, when the generator is operated using AVR the decrease in rpm is greater to -200 . This is due to the strengthening of the generator field current carried out by the AVR so that the output voltage remains closer to the set point. So, the generator rotation becomes heavier.

TABEL II. TEST DATA USING AVR

\begin{tabular}{|c|c|c|c|c|c|}
\hline $\begin{array}{l}\text { Rotation } \\
\text { (rpm) }\end{array}$ & $\begin{array}{c}\text { Axial } \\
\text { Generator } \\
\text { (Volt) }\end{array}$ & $\begin{array}{c}\text { Trafo } \\
\text { (Volt) }\end{array}$ & $\begin{array}{c}\text { Output } \\
\text { AVR } \\
\text { (Volt) }\end{array}$ & $\begin{array}{c}\text { Current } \\
\text { (Ampere) }\end{array}$ & $\begin{array}{c}\text { Load } \\
\text { (Watt) }\end{array}$ \\
\hline 2580 & 24.0 & 185 & 220 & 0.00 & 0 \\
\hline 2480 & 11.6 & 087 & 144 & 0.05 & 15 \\
\hline 2360 & 06.3 & 046 & 076 & 0.07 & 30 \\
\hline 2370 & 11.7 & 088 & 076 & 0.11 & 45 \\
\hline 2441 & 09.1 & 067 & 061 & 0.12 & 60 \\
\hline
\end{tabular}

2. Testing of the axial generator with inner air gap $0.4 \mathrm{~cm}$ and outer $0.5 \mathrm{~cm}$

a. Testing without using AVR in Axial generator with inner air gap $0.4 \mathrm{~cm}$ and outer $0.5 \mathrm{~cm}$.

In this trial phase, the axial generator is given an initial rpm of 2589 with an inner air gap $0.4 \mathrm{~cm}$ and an outer 0.5 $\mathrm{cm}$. Furthermore, the generator is given a gradual increase in load to produce data tests using AVR in Table III as following.

TABEL III. DATA TEST WiTHOUT USING AVR

\begin{tabular}{|c|c|c|c|c|}
\hline $\begin{array}{c}\text { Rotation } \\
\text { (rpm) }\end{array}$ & $\begin{array}{c}\text { Axial } \\
\text { Generator } \\
\text { (Volt) }\end{array}$ & $\begin{array}{c}\text { Trafo } \\
\text { (Volt) }\end{array}$ & $\begin{array}{c}\text { Current } \\
\text { (Ampere) }\end{array}$ & $\begin{array}{c}\text { Load } \\
\text { (Watt) }\end{array}$ \\
\hline 2589 & 45.9 & 354 & 0.00 & 0 \\
\hline 2368 & 34.2 & 263 & 0.07 & 15 \\
\hline 2150 & 24.7 & 185 & 0.12 & 30 \\
\hline 1798 & 17.3 & 135 & 0.15 & 45 \\
\hline 1582 & 12.5 & 091 & 0.16 & 60 \\
\hline
\end{tabular}

When the generator is operated without AVR and given a gradual increase in load from 15 watts to 60 watts with inner air gap $0.4 \mathrm{~cm}$, an outer $0.5 \mathrm{~cm}$ and rpm of 2589 . When the load is above 15 watts and has reached 60 watts so that the output voltage generator began to decrease significantly until it reaches -70 volts and the rpm also decreased to 200 .

b. Testing using AVR in axial generator with inner air gap 0.4 $\mathrm{cm}$ and an outer $0.5 \mathrm{~cm}$.

In this trial phase, the generator is given an initial rpm of 2540 with an inner air gap $0.4 \mathrm{~cm}$ and an outer $0.5 \mathrm{~cm}$. Furthermore, the generator is given a gradual increase in load to produce data tests using AVR in Table IV and Figure 10.

When the generator is operated with using AVR and given a gradual increase in load from 15 watts to 60 watts with inner air gap $0.4 \mathrm{~cm}$, outer $0.5 \mathrm{~cm}$, and rpm of 2540 . When the load is above 15 watts and has reached 60 watts so that the output voltage begins to decrease but not as high as when the generator is operated without AVR. The decrease in the output voltage generator just reaches -70 volts. In contrast to when the generator is operated using AVR the decrease up to 
-3- volt. But when the generator is operated with AVR the decrease of rpm is greater until reaches -220 . This is due to the strengthening of the generator field current carried out by the AVR so that the output voltage remains closer to the set point. So, the generator rotation becomes heavier.

\section{TABEL IV. DATA TEST USING AVR}

\begin{tabular}{|c|c|c|c|c|c|}
\hline $\begin{array}{c}\text { Rotation } \\
(\mathrm{rpm})\end{array}$ & $\begin{array}{c}\text { Axial } \\
\text { Generator } \\
\text { (Volt) }\end{array}$ & $\begin{array}{c}\text { Trafo } \\
\text { (Volt) }\end{array}$ & $\begin{array}{c}\text { Output } \\
\text { AVR } \\
\text { (Volt) }\end{array}$ & $\begin{array}{c}\text { Current } \\
\text { (Ampere) }\end{array}$ & $\begin{array}{c}\text { Load } \\
\text { (Watt) }\end{array}$ \\
\hline 2540 & 42.3 & 328 & 296 & 0.00 & 0 \\
\hline 2355 & 33.2 & 255 & 230 & 0.06 & 15 \\
\hline 1699 & 11.3 & 078 & 126 & 0.10 & 30 \\
\hline 1188 & 11.1 & 088 & 081 & 0.11 & 45 \\
\hline 1173 & 10.3 & 075 & 068 & 0.13 & 60 \\
\hline
\end{tabular}

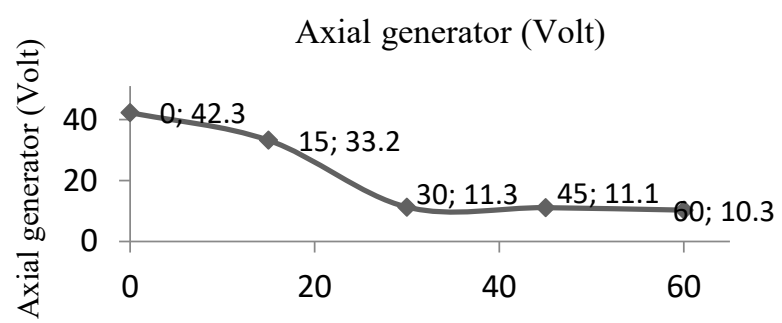

Load (Watt)

Fig. 10. Axial generator load voltage graph.

The use of AVR in a 1 phase axial generator makes the output voltage of the generator stable as long as it is not overloaded. So that the excitation voltage can meet the needs of the generator when the generator is receiving a large load, it needs a sufficient rpm so that the AVR can still control the generator so that the output voltage matches the desired set point. If the generator excitation voltage is sufficient, even though the generator is given a load of up to 60 watts, the output voltage of the generator will remain stable according to the desired set point.

If the load on the generator increases, it will be increased by the AVR so that the generator output voltage does not go down. Vice versa if the load in the generator is reduced it will be reduced by the AVR so that the generator output voltage does not exceed the desired set point. Because basically, the working principle of AVR is to control the generator voltage supplied from the excitation so that if the input from the excitation unit is less than the generator needs, the generator output voltage will decrease because the AVR is not equipped with an inverter circuit that can increase the voltage. If the excitation voltage value exceeds the needs of the generator, the AVR will reduce the excitation voltage. Automatically so that the generator output voltage does not exceed the specified setpoint.

\section{CONCLUSION}

Inner air gap distance of $0.4 \mathrm{~cm}$ and outer $0.5 \mathrm{~cm}$ affect the $\mathrm{rpm}$ and unstable voltage. The effect of the use of AVR through the increase in load in the generator compared to the generator that does not use AVR is that the generator is operated using AVR the output voltage will be stable according to the desired setpoint as long as the excitation voltage.

\section{REFERENCES}

[1] S. Saha, M. E. Haque, and M. A. Mahmud, "Diagnosis and Mitigation of Sensor Malfunctioning in a Permanent Magnet Synchronous Generator Based Wind Energy Conversion System," IEEE Trans. Energy Convers., vol. 33, no. 3, pp. 938-948, 2018.

[2] M. M. Chowdhury, M. E. Haque, S. Saha, M. A. Mahmud, A. Gargoom, and A. M. T. Oo, "An Enhanced Control Scheme for an IPM Synchronous Generator Based Wind Turbine With MTPA Trajectory and Maximum Power Extraction," IEEE Trans. Energy Convers., vol. 33, no. 2, pp. 556-566, 2018.

[3] F. Grimaccia, G. Gruosso, M. Mussetta, A. Niccolai, and R. E. Zich, "Design of tubular permanent magnet generators for vehicle energy harvesting by means of social network optimization," IEEE Trans. Ind. Electron., vol. 65, no. 2, pp. 1884-1892, 2018.

[4] M. Flankl, A. Tüysüz, and J. W. Kolar, "Cogging Torque Shape Optimization of an Integrated Generator for Electromechanical Energy Harvesting," IEEE Trans. Ind. Electron., vol. 64, no. 12, pp. 9806-9814, 2017.

[5] N. Nguyen-Hong, H. Nguyen-Duc, and Y. Nakanishi, "Optimal Sizing of Energy Storage Devices in Isolated Wind-Diesel Systems Considering Load Growth Uncertainty," IEEE Trans. Ind. Appl., vol. 54, no. 3, pp. 1983-1991, 2018.

[6] L. Guo et al., "Energy Management System for Stand-Alone WindPowered-Desalination Microgrid," IEEE Trans. Smart Grid, vol. 7, no. 2, pp. 1079-1087, 2016.

[7] Y. Liang and Y. Yang, "Performance Analysis of 10-MW HTS Wind Generator Based on 2D Transient FEA," IEEE Power Energy Technol. Syst. J., vol. 4, no. 1, pp. 10-15, 2016.

[8] M. Ali, M. R. Djalal, M. Fakhrurozi, Kadaryono, Budiman, and D. Ajiatmo, "Optimal Design Capacitive Energy Storage (CES) for Load Frequency Control in Micro Hydro Power Plant Using Flower Pollination Algorithm," 2018 Electr. Power, Electron. Commun. Control. Informatics Semin. EECCIS 2018, pp. 21-26, 2018.

[9] H. Suyono, M. Shidiq, A. N. Ferdianzah, T. Utomo, I. Musirin, and L. J. Awalin, "Dynamic Stability Impact of the Hybrid Wind and Microhydro Renewable Energy Sources on the Distribution System," 2018 Electr. Power, Electron. Commun. Control. Informatics Semin. EECCIS 2018, pp. 15-20, 2018.

[10] A. K. Barik and D. C. Das, "Active power management of isolated renewable microgrid generating power from Rooftop solar arrays, sewage waters and solid urban wastes of a smart city using Salp swarm algorithm," Int. Conf. Technol. Smart City Energy Secur. Power Smart Solut. Smart Cities, ICSESP 2018 - Proc., vol. 2018-Janua, pp. 1-6, 2018.

[11] T. Xia, H. Yu, R. Guo, and X. Liu, "Research on the Field-Modulated Tubular Linear Generator with Quasi-Halbach Magnetization for Ocean Wave Energy Conversion," IEEE Trans. Appl. Supercond., vol. 28 , no. $3,2018$.

[12] S. Kumar Tiwari, B. Singh, and P. K. Goel, "Design and Control of Microgrid Fed by Renewable Energy Generating Sources," IEEE Trans. Ind. Appl., vol. 54, no. 3, pp. 2041-2050, 2018.

[13] A. Merabet, K. T. Ahmed, H. Ibrahim, and R. Beguenane, "Implementation of Sliding Mode Control System for Generator and Grid Sides Control of Wind Energy Conversion System," IEEE Trans. Sustain. Energy, vol. 7, no. 3, pp. 1327-1335, 2016.

[14] M. Chinchilla, S. Arnaltes, and J. C. Burgos, "Control of permanentmagnet generators applied to variable-speed wind-energy systems connected to the grid," IEEE Trans. Energy Convers., vol. 21, no. 1, pp. 130-135, 2006.

[15] N. Georgiev, D. Iordanov, and S. Stoianov, "Single-phase two-rotor axial generator with rotating permanent magnets in the stator," 2018 20th Int. Symp. Electr. Appar. Technol. SIELA 2018 - Proc., pp. 1-4, 2018.

[16] M. A. Dranca, M. Chirca, S. I. Cosman, and S. Breban, "Design analysis of a permanent magnet brushless generator with two counter rotating rotors for small-wind turbine," 2018 Int. Conf. Appl. Theor. Electr. ICATE 2018 - Proc., pp. 1-5, 2018.

[17] L. A. J. Friedrich, J. J. H. Paulides, and E. A. Lomonova, "Modeling and Optimization of a Tubular Generator for Vibration Energy Harvesting Application," IEEE Trans. Magn., vol. 53, no. 11, pp. 15, 2017.

[18] S. Wei, Y. Zhou, and Y. Huang, "Synchronous Motor-Generator Pair to Enhance Small Signal and Transient Stability of Power System with High Penetration of Renewable Energy," IEEE Access, vol. 5, no. c, 
pp. 11505-11512, 2017.

[19] D. Liu, H. Polinder, A. B. Abrahamsen, and J. A. Ferreira, "Topology Comparison of Superconducting Generators for 10-MW Direct-Drive Wind Turbines: Cost of Energy Based," IEEE Trans. Appl. Supercond., vol. 27, no. 4, pp. 1-7, 2017.

[20] V. A. Demidov et al., "Test of Device Based on Disk Magnetocumulative Generator DMCG480 With Explosive Current Opening Switch," IEEE Trans. Plasma Sci., vol. 45, no. 10, pp. 2674 2677, 2017.

[21] P. Tokat and T. Thiringer, "Sizing of IPM Generator for a Single Point Absorber Type Wave Energy Converter," IEEE Trans. Energy Convers., vol. 33, no. 1, pp. 10-19, 2018.

[22] L. Pravica, F. Jukić, T. Bariša, and S. Stipetić, "Interior Permanent Magnet Wind Generator Torque Estimation Considering Low-Pass Filter Phase Shift Compensation," 2018 Int. Symp. Ind. Electron. INDEL 2018 - Proc., pp. 1-5, 2019.

[23] Y. S. Park, M. M. Koo, S. M. Jang, J. Y. Choi, and D. J. You, "Performance evaluation of radial- and axial-flux PM wind power generators with mechanical energy storage system," IEEE Trans. Energy Convers., vol. 30, no. 1, pp. 237-245, 2015.

[24] Q. Shuheng and W. Haifeng, "Simulation of Tubular Transverse Flux Permanent Magnet Linear Generator," ICEMS 2018 - 2018 21st Int. Conf. Electr. Mach. Syst., pp. 1766-1770, 2018.

[25] M. Ostroverkhov, V. Chumack, and E. Monakhov, "Axial flux permanent magnet controlled generator," 2018 IEEE 3rd Int. Conf. Intell. Energy Power Syst. IEPS 2018 - Proc., vol. 2018-Janua, no. July, pp. 353-357, 2018.

[26] A. A. Yusuf, M. Irfan, and M. F. Razzaq, "A design of coreless permanent magnet axial flux generator for low speed wind turbine," Int. Conf. Electr. Eng. Comput. Sci. Informatics, vol. 2018-Octob, pp. 637-641, 2018. 